\title{
Toward professional development for teachers grounded in a theory of decision making
}

\author{
Alan H. Schoenfeld
}

Accepted: 16 January 2011/Published online: 4 February 2011

(C) The Author(s) 2011. This article is published with open access at Springerlink.com

\begin{abstract}
There is now robust evidence that teachers' and others' in-the-moment decision making can be modeled and explained as a function of the following: their knowledge and other intellectual, social, and material resources; their goals; and their orientations (their beliefs, values, and preferences). The role of beliefs as they affect teachers' behavior can thus be described at a level of mechanism-but of necessity in interaction with resources and goals. This paper outlines and exemplifies how resources, goals, and orientations shape teachers' behavior. It indicates how they are interconnected, and why their evolution is necessarily slow. It then suggests how these understandings can be used as a foundation for mathematics teachers' professional development, and describes how they are being used to shape a course of participatory professional development for middle school mathematics teachers.
\end{abstract}

Keywords Mathematics teaching - Decision making · Resources · Goals · Beliefs · Orientations · Modeling · Professional development

\section{Introduction}

The main theoretical argument in which this paper is grounded is that people's behavior in "well-practiced" domains - teaching in particular-can be understood as a function of their knowledge and resources, goals, and beliefs and orientations (Schoenfeld, 2010). "Well-

A. H. Schoenfeld $(\square)$

School of Education, EMST, University of California, Tolman Hall \# 1670, Berkeley, CA 94720-1670, USA

e-mail: alans@berkeley.edu practiced" domains are those areas of practice in which individuals have had enough time to develop a corpus of knowledge and routines that shape much of what they do. Any professional practice is an example: the day-to-day activities of teachers, doctors, automobile mechanics, secretaries, and chefs are supported by routines that they have developed, over time, to handle recurring issues of practice. (The same is true for home cooks, and hobbyists; a very large part of what people do in general is well practiced.) The theory is general, but as a mathematics educator my primary focus is on the improvement of mathematics teaching and learning. Thus, the examples that follow are of mathematics teaching. My goal in the first part of this paper is to indicate how the interplay of resources, goals, and orientations results in teachers' in-the-moment choices as they teach. That is, although beliefs (or more broadly, orientations) are an essential factor in shaping teachers' behavior, they cannot be considered in isolation. In the second part, I describe some attempts to use these theoretical ideas to help shape teachers' professional development. Descriptions of the theory and of practical implications in what follows are drawn in part from Schoenfeld (1998, 2000, 2010, 2011). ${ }^{1}$

\footnotetext{
${ }^{1}$ I note that Schoenfeld (2010), which summarizes more than a decade of research by Berkeley's Teacher Model Group, contains more than 100 pages of detailed, line by line analyses of classroom transcripts, which provide the analytic grounding for the summary statements that appear in this paper. Thus, what may appear as assertional in this paper is only so for lack of space: the warrants for the analytic claims made here can be found in that book and the other, more extended analytic papers listed in the references. This paper focuses on implications and applications.
} 


\section{Background and context: contextualizing teacher beliefs and decision making}

Issues of people's decision making have been the subject of research for many decades, both in general (e.g., Kahnemann, Slovic, and Tversky, 1982; Newell and Simon, 1972; Savage, 1954) and more specifically with regard to teaching. In the literature on teaching one finds generally encompassing volumes such as the third edition of the Handbook of Research on Teaching (Wittrock, 1986), which includes a review chapter focusing on teachers' thought processes (Clark \& Peterson, 1986) and the fourth edition of the Handbook (Richardson, 2001), which contains a chapter by Munby, Russell, \& Martin (2001) on "teachers' knowledge and how it develops." Volume 20 of the Review of Research in Education (Darling-Hammond, 1994) includes a collection of articles devoted to teachers' knowledge and practice. The Handbook of Research on Mathematics Teaching and Learning (Grouws, 1992) includes reviews of classroom culture, the effects of teaching practices, teachers' beliefs, and teacher knowledge; especially relevant are reviews of teacher knowledge by Fennema and Franke (1992) and of teacher beliefs by Thompson (1992). The Handbook of Educational Psychology (Berliner \& Calfee, 1996) contains descriptions of teachers' beliefs and knowledge (Calderhead, 1996) and descriptive models of the teaching process (Borko \& Putnam, 1996), as does the Second Handbook of Research on Mathematics Teaching and Learning (Lester, 2007). More specifically, there is a large literature on beliefs and belief systems, both with regard to mathematical problem solving (see, e.g., Schoenfeld, 1983, 1985 ) and in the teaching of mathematics (the mathematics-specific papers listed above; see also Aguirre and Speer, 2000; Leder, Pehkonen, \& Toerner, 2002; Philipp, 2007, for a recent comprehensive review).

My purpose in this brief section is to situate the theoretical underpinnings of this paper relative to that body of work and to the current volume, and to establish the context for the discussion of theory that follows. From my perspective, the literature on beliefs, specifically in teaching, has been largely descriptive, often focusing on teachers' professed beliefs - and because of this, the literature is of limited utility (for a discussion, see Schoenfeld, 2002). In a comprehensive review of research on teachers' epistemological beliefs, e.g., Schraw and Olafson (2002) found few clear links between teachers' characterizations of their epistemological world views and reports of their teaching practices. That is, Schraw and Olafson found significant differences between what teachers say they believe and what the teachers describe themselves as actually doing in the classroom. Part of the reason is explained by a well known paper by David Cohen (1990). The teacher in
Cohen's study, whom he calls Mrs. Oublier, had taken some professional development workshops that, from her perspective, had revolutionized her teaching: rather than teaching in the old, traditional way, Mrs. Oublier "explored methods to engage students in actively understanding mathematics... Mrs. O was delighted with her students' performance, and with her own accomplishments" (Cohen, 1990, p. 311). Yet, according to Cohen's analysis, Mrs. Oublier "used the new materials, but used them as though mathematics contained only right and wrong answers. She has revised the curriculum to help students understand math, but she conducts the class in ways that discourage exploration of students' understanding." In short, Mrs. Oublier's pedagogical practices were only partly in synch with her pedagogical beliefs. Or, to be more precise, her professed beliefs were only partially enacted in the classroom.

From my perspective, what matters in teaching is not so much what people say but what they do. Thus, although professed beliefs are important, what is important from my perspective is the triangulation of claims about teachers' beliefs (whether their own professed beliefs or the beliefs attributed to them by researchers; see, e.g., Speer, 2005) with the teachers' actual classroom behavior. A notable example of such triangulation may be found in Swan (2006), which documents changes in teachers' beliefs and practices from the point of view of the teacher, the researcher, and the teacher's students.

My research program, for more than 20 years, has focused on understanding and then modeling teachers' teachers' decision making during teaching. The act of modeling is a form of triangulation-the underlying questions being, what explanatory constructs can be used to characterize teachers' actions; how do they interact; and can one provide models that explain teachers' actions, on a very fine-grained (e.g., line by line of videotape) basis? Some of the work, as it has evolved, can be found in Schoenfeld (1998, 2000, 2008). The theory, with case studies modeled and argued on a line by line basis, is presented in my book, How We Think (Schoenfeld, 2010).

In general terms, here is how that research program fits with the literature and the current volume. My main analytic focus is on how and why teachers make the choices they make, as they teach. Two key features of this focus are essential. First, and an expansion of the concerns in the literature, is the quest for a sense of mechanism. As noted above, the vast majority of studies in the literature on beliefs and other factors that affect teachers' behavior is descriptive and/or correlational. Yes, it is important to understand that beliefs play a role in teachers' decision making, but how do they do so? A paper like Aguirre \& Speer (2000) plays a role in that agenda: Aguirre and Speer indicate that clusters of beliefs play a role in shaping 
decision making, and their paper begins to specify how. Note that this makes good sense: it is belief systems, not isolated beliefs, that shape problem solving behavior (Schoenfeld, 1985). I note as well that the work by Aguirre and Speer contributed directly to the work that serves as the specific background for this article: Aguirre and Speer were members of the Teacher Model group at Berkeley, and their article appeared in a special issue of the Journal of Mathematical Behavior (Schoenfeld, 2000) that set out the modeling enterprise that came to fruition in Schoenfeld (2010). A steppingstone along the way was the line by line analysis of a full hour's teaching by Deborah Ball in Schoenfeld $(2008,2010)$. In those analyses, as in Aguirre \& Speer (2000), clusters or systems of beliefs play a role-but the mechanisms by which they play that role were explored in much greater depth. What one sees in those analyses is that certain situations or the activation of certain beliefs trigger the activation of families of closely related beliefs, and it is these families or clusters of beliefs that contribute to the choices that teachers make.

But, note that I say contribute to. That is because beliefs alone cannot completely shape behavior: what one does is a function of what one decides are the most important things to do (the goals one sets, consistent with one's beliefs) and the resources that one has at one's disposal. Therein lies the relationship between this article and the other articles in this special issue. On the one hand, as the theory indicates, beliefs (or more broadly, orientations) are a central determining factor of teachers' behavior. How they come into being, how they are shaped or evolve, and how they operate are questions of fundamental importance. On the other hand, we (or at least I) study beliefs for a reason: we have a vision of effective teaching, and we would like to help teachers move toward that vision. For that purpose, understanding beliefs is not enough. (The same is true, of course, for descriptions of teacher knowledge, or the other categories typically discussed in the general literature referenced above.) To make a medical analogy: just as a special issue on "the lung and its role in respiration" must of necessity discuss the circulatory system, a discussion of how teachers make the highly consequential choices do, as they teach, must extend beyond beliefs and orientations to give a sense of the "whole picture." The question is, how do beliefs work and what do they interact with?

At the same time, there are significant limitations to a focus on decision making "in the moment." The question for the modeling enterprise is "what contributes to the decisions the person is making right now?" As such, it does not address the larger questions of context and history-how did the teacher come to have the resources, beliefs and orientations, goals that he or she has? How does the school context, or the national context, affect what the teacher believes is possible, and shape what he or she feels must be done (see, e.g., Borko, Eisenhart, Brown, Underhill, Jones, \& Agard, 1992; Leder, Pehkonen, \& Toerner, 2002)? Here, of course, there is much that the current volume offers that goes beyond the scope of this paper.

In the next two sections of this paper I present distilled descriptive versions of some of the cases in Schoenfeld (2010), to convey the basic ideas behind the theory. Readers interested in the analytic detail may wish to consult the resources cited in this section.

\section{Theory, part I: the nature of people's in-the-moment decision making}

The central components of the theory are an individual's resources, goals, and orientations. What is critical is how they interact.

An individual's resources include his or her knowledge, but also include the social and material resources that are available to him or her. The role of knowledge is obvious; what the teacher knows and does not know provides both affordances and constraints regarding what he or she can do in the classroom. There are, as discussed in the literature, various kinds of knowledge, e.g., content knowledge, general pedagogical knowledge, and pedagogical content knowledge; but such distinctions are, in a non-trivial sense, "academic." What matters in teaching is that a teacher's "knowledge inventory" includes the information that he or she can potentially bring to bear in a teaching situation. Material resources matter as well: e.g., the teacher who has up-to-date technology available in the classroom has a different set of options available than the teacher whose classroom lacks such materials. Finally, the resources a teacher brings to the classroom include personal and interpersonal skills and connections. For example, this past year, when I was asked a question about how to deal with certain behavioral issues in the classroom, I did not have a good answer to the question - but I knew that the colleague who runs our teacher preparation program would be able to conduct a robust discussion of the issue. I invited him to join us, and the students in my class benefited from the discussion.

Goals are the things that people consciously or unconsciously set out to achieve. Functionally speaking, "goals recruit resources"; people act in the service of the goals they have established by selecting and implementing resources that will enable them to satisfy those goals. Goals operate at multiple levels, and at any given moment a teacher's actions can be seen as consistent with a range of goals at various levels of grain size. 
Decision making during teaching can be seen as the selection of goals consistent with the teacher's resources and orientations. To give a simple and familiar example, imagine a classroom in which a student performing a calculation has just written

$(a+b)^{2}=a^{2}+b^{2}$.

How the teacher reacts will depend on a number of things-specifically, on the teacher's resources and orientations. How much time is left in the lesson? Does the teacher consider this to be a minor issue, or perhaps that the mistake indicates a more serious problem? How important does the teacher think it is to work through the student's error? What explanations does the teacher have at his or her disposal? (e.g., there is a simple algebraic argument using the distributive law; there are more extended arguments using area models, etc.) Does the teacher believe there is ample time to work through one or more explanations, and that it would be worth doing so? Or will the teacher, feeling pressure to keep up with the day's proposed schedule, simply correct the student and move on with the lesson as planned? Whatever the decision, the result will be a modified set of goals, which then recruit the appropriate resources. If the teacher decides that (i.e., selects the goal that) the error should be pursued in depth, then the current goal is put on hold, and the goal of pursuing the error in depth is given highest priority. The teacher then implements the approach(es) consistent with that decision, after which the teacher returns to the goal that had been put on hold. If the decision is simply to remind the student of the fact that $(a+b)^{2}=a^{2}+2 a b+b^{2}$, the teacher does so (prioritizing and then satisfying a goal that is only active for a few seconds) and then continues the previous plan of action, in the service of the previous goal. As this example suggests, every sequence of actions can be seen as consistent with a series of goal prioritizations that are grounded in the teacher's beliefs and orientations, and the selection, once a goal has been given highest priority, of resources intended to help achieve that goal.

Orientations is a broad category that includes beliefs, values, preferences, and tastes. Here, I explain why I have moved from the use of the term beliefs to the use of orientations, and how orientations function in problem solving. Starting with my early work in problem solving (Schoenfeld, 1983, 1985), I used the term beliefs to refer to perceptions on the part of individuals that shape the ways in which they frame or orient themselves to any particular context, and thus shape they ways they act in that context. For example, students who have been accustomed to working dozens of mathematics homework "problems" each night, and to taking examinations in which there are a large number of problems to be worked in an hour, tend to develop the belief that "all mathematics problems can be solved in just a few minutes"-and, as a behavioral corollary to this belief, they tend to stop working on problems if they are unable to solve them in short order. ${ }^{2}$

Similarly, teachers develop understandings and perceptions about the nature of mathematics, about pedagogy, and about students on the basis of their experience, and those beliefs/orientations shape their teaching practices. For example, the teacher who believes that mathematical proficiency consists of the ability to implement various mathematical procedures will emphasize very different things in instruction than the teacher whose primary emphasis is conceptual understanding. And, the teacher's perception of the students will make a big difference as well. One year I asked a teacher whose class I had observed, and whose approach to teaching that class had been very procedurally oriented ("Step 1 . Draw a line from point P to point Q. Step 2. ..."), if he would consider giving the students a problem without prior preparation, knowing that they might need to struggle with it. "Not these students," he said; "it would just confuse them. I might do that with my honors students, but not these." That is, his perception of his students' abilities, and his beliefs about the kind of pedagogy appropriate for students with such abilities, resulted in his choice of pedagogy for these students.

In general, I shall employ the term "orientations" rather than "beliefs," because the latter term is more general. Table 1 provides a general description of in-the-moment decision making. Although the examples given in this paper as illustrations of the theory are all instances of mathematics teaching, the theory of decision making is more general: as noted above, I claim (see Schoenfeld, 2010) that the process described in Table 1 applies to in-the-moment decision making in all well-practiced domains, including teaching, cooking, automobile mechanics, and medical practice. A doctor's choices may be shaped by whether the doctor is oriented toward preventative medicine, or treating problems when they become manifest. One mechanic may prefer to mend or repair parts while fixing cars, while another may prefer to replace old parts with new ones, even if the old ones can be repaired. A cook may simply like some foods more than others, or prefer some methods of preparation to others (say, steaming rather than sautéing, or vice versa). In these arenas, referring to "beliefs" sometimes seems awkward. For that reason I use the term orientations.

Table 1 provides the broad structure of the theory. As summarized here, it may seem rather simplistic. What matters is that people's decision making during

\footnotetext{
${ }^{2}$ In modeling people's beliefs/orientations and decision making, I do not claim that people consciously hold or affirm such beliefs, but rather that their behavior is consistent with their holding them.
} 
Table 1 How things work, in general

An individual enters into a particular context with a specific body of resources, goals, and orientations

The individual takes in and orients to the situation. Certain pieces of information and knowledge become salient and are activated

Goals are established (or reinforced if they pre-existed)

Decisions consistent with these goals are made, consciously or unconsciously, regarding what directions to pursue and what resources to use

If the situation is familiar, then the process may be relatively automatic, where the action(s) taken are in essence the access and implementation of scripts, frames, routines, or schemata

If the situation is not familiar or there is something non-routine about it, then decision making is made by a mechanism that can be modeled by (i.e., is consistent with the results of) using the subjective expected values of available options, given the orientations of the individual Implementation begins

Monitoring (whether effective or not) takes place on an ongoing basis

This process is iterative, down to individual utterances or actions

Routines aimed at particular goals have sub-routines, which have their own subgoals

If a subgoal is satisfied, the individual proceeds to another goal or subgoal

If a goal is achieved, other goals take priority via decision making

If the process is interrupted or things don't seem to be going well, decision making kicks into action once again. This may or may not result in a change of goals and/or the pathways used to try to achieve them

Reproduced, with permission, from Schoenfeld (2010)

well-practiced activities such as teaching can be modeled, on a line by line basis, using this approach. Details may be found in Schoenfeld (2010). In what follows I give a few examples to suggest how things work, before turning to applications.

Here, I provide two brief examples to suggest the ways in which resources, goals, and orientations interact. These are summary descriptions from cases discussed at length in Schoenfeld (2010).

In the first case, Mark Nelson was a beginning teacher who is teaching an elementary algebra class in which his students are learning the laws of exponents. Nelson was working from a traditional textbook, which focused on formulas and procedures; he wanted the students to understand where the formulas come from. In the first part of the lesson, he showed his students how to work through exercises such as

$x^{5} / x^{3}=?$

by having them first expand the numerator and denominator and "cancel:"

$$
\frac{x^{5}}{x^{3}}=\frac{x \cdot x \cdot x \cdot x \cdot x}{x \cdot x \cdot x}=\frac{x \cdot x \cdot \not x \cdot \not x \cdot \not x}{\not x \cdot \not x \cdot \not x}=x^{2} .
$$

He then showed them that canceling was equivalent to subtracting exponents:

$\frac{x^{5}}{x^{3}}=x^{5-3}=x^{2}$.

Having done so he assigned the students the following problems to work by themselves: $m^{6} / m^{2}, x^{3} y^{7} / x^{2} y^{6}$, and $x^{5} / x^{5}$. The discussion of the first two problems went smoothly, but he ran into major difficulties in the discussion of $x^{5} / x^{5}$.

Nelson and the class expanded $x^{5} / x^{5}$ and "canceled," resulting in the following expression on the board.

$$
\frac{x^{5}}{x^{5}}=\frac{x \cdot x \mid x \cdot x \cdot x \cdot x \cdot x}{x \cdot x \cdot x \cdot x}
$$

When he asked "What do I have?" he expected to hear a " 1 " from the students, after which he intended to have the students complete the derivation he wanted, $x^{0}=1$, by subtracting exponents. Instead the students responded "zero," "zip," "nada," and "nothing" to his questionand they were completely unreceptive to his attempts to get them to see the "1." For example, he wrote " $5 / 5$ " on the blackboard and asked "What's 5/5?" The class responded " 1 " as he canceled the 5's in the numerator and denominator. "But I cancelled," he said. "If there's a 1 there (pointing to 5/5), isn't there a 1 there (pointing to the cancelled expression above)?" "No," the students chorused. Completely defeated, he slumped at the blackboard board as students argued there's "nothing there."

The issue for analysis is this. Nelson knew the relevant mathematics and he could have easily shown the students that

$\frac{x^{5}}{x^{5}}=\left(\frac{x}{x}\right)^{5}=1^{5}=1$.

Yet, he did not do so. The question is why. The reasonwhich we discovered in the co-analysis of the lesson with Nelson-was that at the time he taught this lesson Nelson 
held a very strong (although unarticulated) belief about what is appropriate to tell students when one is teaching mathematics. A beginning teacher, Nelson wanted ideas to "come from" his students, rather than from him. He felt very comfortable providing explanations of things students said, once they had said them-thus, when a student had said he obtained a result by subtracting exponents, Nelson provided an explanation of why it was mathematically appropriate to subtract the exponents. Nelson was fully prepared to explain why

$$
\frac{x|x| \cdot x \cdot x \cdot k}{x \cdot x \cdot k \cdot x \cdot x}
$$

was equal to one, once a student said that it was equal to one. But, when none of the students in the class said "one" in response to his question "What do I have?" he felt that he did not have "permission" to provide his explanation. That would have been be introducing new material rather than building on what the students had said.

A second case stands in contrast. Jim Minstrell, a highly experienced and accomplished teacher, was teaching a class that dealt with measures of central tendency (mean, median, and mode). The question the class was considering was how to determine the "best number" to represent the width of a table, after eight students had each measured the table's width and obtained the values 106.8, 107.0, 107.0, $107.5,107.0,107.0,106.5$, and $106.0 \mathrm{~cm}$. The class had discussed the mean and median as possible ways to combine the numbers when a student said,

"This is a little complicated but I mean it might work.

If you see that 107 shows up 4 times, you give it a coefficient of 4 , and then 107.5 only shows up one time, you give it a coefficient of one, you add all those up and then you divide by the number of coefficients you have."

There is a wide range of possible responses to this comment, ranging from "That's a very interesting question. I'll talk to you about it after class" to engaging the class in extended conversation about the possible meaning and utility of the student's suggestion. (Note that there are two interpretations of "divide by the number of coefficients you have." All told, there are eight coefficients, but there are five different ones. If the student's comment is interpreted to mean dividing by eight, then the student has suggested the "weighted average," a rather nice discovery; but if it is interpreted to mean five, the suggestion is not mathematically productive.)

As a teacher, Minstrell was oriented toward inquiry and sense making; he perceived it as important for his students to be able to pursue ideas such as the one raised by the student. He also possessed the content and pedagogical content knowledge to be able to recognize the mathematical issues involved in the discussion, and to orchestrate an interactive conversation in which the students contributed to the analysis under his subtle direction. As was the case with Nelson, Minstrell's orientations (beliefs and values) shaped the direction his lesson took-but, he was able to pursue the goals he established because of the richness of his knowledge base.

A key point with regard to teachers' development is that people's resources, goals, and orientations are deeply intertwined. In both the cases described above, the teachers' orientations resulted in their establishing (in the moment) certain goals for the ways that the classroom conversation would evolve. Nelson's need to have the content of his lesson emerge from student comments put him in an untenable position when the students did not provide him with what he needed; his lack of resources kept him from taking the steps he felt he needed to take. In contrast, Minstrell was able to move flexibly toward his goals precisely because of his command of resources. Being able to recognize the correct and incorrect mathematical possibilities in the student's statement, and having at his disposal dialogic strategies that help the students generate the information he wants to work with, allowed Minstrell to move successfully toward the results he wanted to achieve.

A corollary to this point is that the development of teaching expertise, like the development of all expertise, must of necessity be a long and slow process. A great deal of pedagogical content knowledge is required to achieve the kinds of pedagogical goals that Minstrell had, and to which Nelson aspired.

\section{Theory, part II: teachers' developmental trajectories}

As Stigler and Hiebert (1999) have noted, there is much greater variance in teaching styles between nations than there is variance within nations. In different countries, different styles of teaching (e.g., depending on well-constructed lectures as the primary form of instruction, or depending on having students interact with each other) may be valued differently. Thus, the ideals to which teachers aspire will vary; and the trajectories toward those ideals will vary. In what follows, then, I am not suggesting a universal trajectory, but, rather, one that is consistent with my values as a researcher and professional developer, and that is consistent with developmental trajectories in the United States and some other nations (see, e.g., Fuller, 1969; Hord, Rutherford, Huling-Austin, \& Hall, 1987; Ryan, 1986; Smith, 2000). 
From my perspective, a particular form of teaching expertise that is highly valuable and worth aspiring to is the ability to conduct "diagnostic teaching." This kind of teaching, in which teachers make significant use of formative assessment to see what their students understand, and shape their lessons according to what they discover about their students, was exemplified by Minstrell in the vignette above. Minstrell's lesson, and the lesson by Ball discussed in Schoenfeld (2008, 2010), exemplify the productive use of pedagogical content knowledge as first described by Shulman $(1986,1987)$, and are instances of the kind of teaching described in the US National Council of Teachers of Mathematics' (1991) Professional Standards for teaching mathematics. In diagnostic teaching (or, teaching with a heavy emphasis on using formative assessments), the teacher has specific mathematical goals. In addition, the teacher recognizes that students have varied understandings of the mathematics under discussion. He or she probes for what the students know and then responds in ways that address errors and misconceptions, and that build on student understanding, to move the students toward the instructional goals. (Note that this kind of flexible, responsive teaching is a form of "adaptive expertise" as described by Hatano \& Inagaki, 1986.)

Diagnostic teaching is a form of instruction to which some teachers in the US aspire. This form of teaching is not well supported by typical teacher preparation programs, or what are called "in-service" or ongoing professional development programs for teachers. In the US, aspiring teachers most often obtain their teaching credentials as either (a) part of their undergraduate education or (b) in a fifth year that focuses largely on "teaching methods," after they have obtained an undergraduate degree. (Requirements vary in different states.) Once they have passed licensure examinations, new teachers are assigned their own classrooms, with relatively little opportunity to be mentored or, more generally, to interact with other teachers. (This contrasts strongly with opportunities for collegial interactions in Japan, for example.) Indeed, one could argue that diagnostic teaching (i.e., anticipating student responses and building productively on them) is a core principle of lesson study (see, e.g., Fernandez \& Yoshida, 2004).

In the US, one sees typical development toward diagnostic teaching as represented in Figs. 1, 2, and 3. Each figure includes three planes of teacher activities: "managing" the classroom, having students engage in mathematically productive and (one hopes) engaging activities, and engaging in diagnostic teaching. Typically, beginning teachers in the US are still learning to "manage" classroom activities, and a large amount of their time and attention is devoted to this: see Fig. 1.

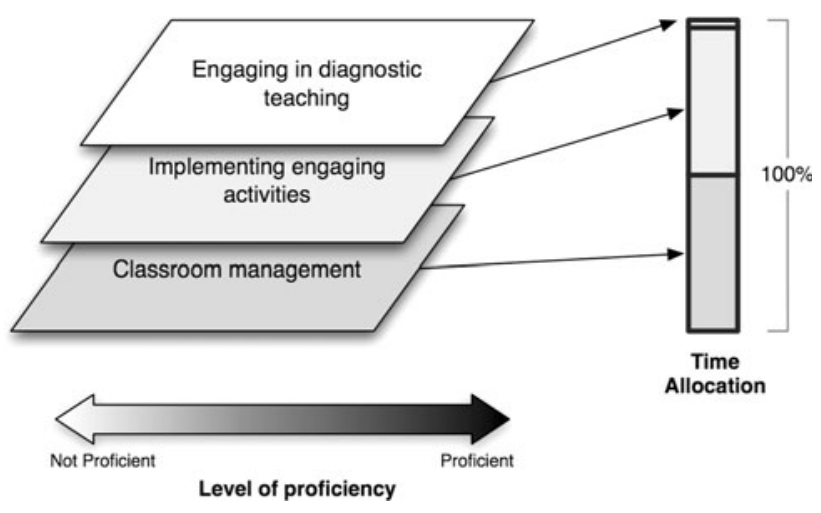

Fig. 1 Levels of proficiency and time allocations of a typical beginning teacher. (The degree of shading in the planes represents the level of proficiency, and the arrows point to the percentage of time devoted to each plane of activity.) Reprinted with permission from Schoenfeld (2010)

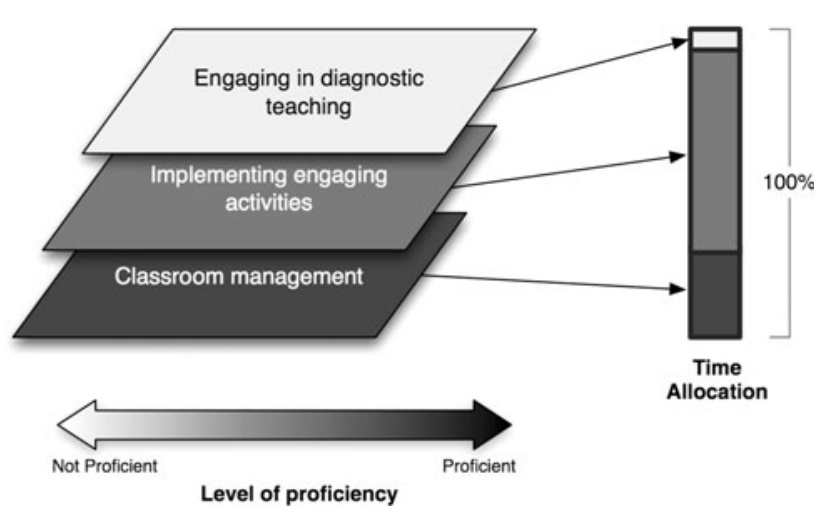

Fig. 2 Levels of proficiency and time allocations of a typical accomplished teacher. (The degree of shading in the planes represents the level of proficiency, and the arrows point to the percentage of time devoted to each plane of activity.) Reprinted with permission from Schoenfeld (2010)

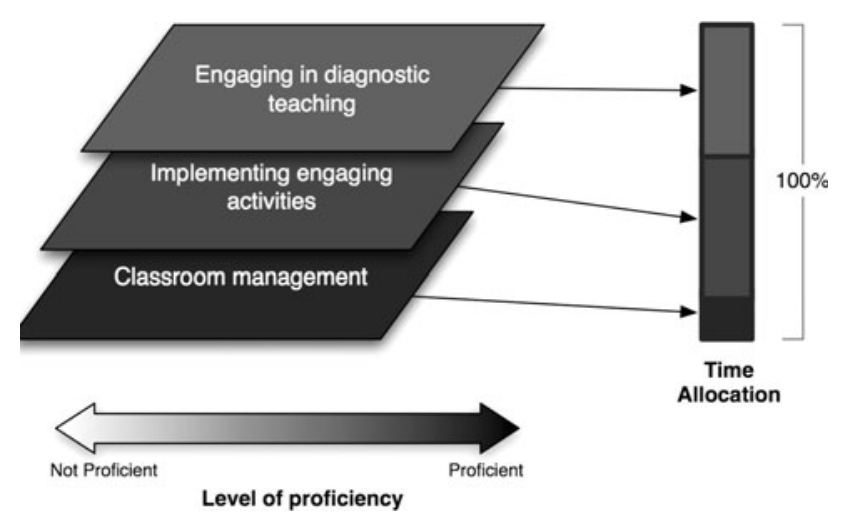

Fig. 3 Levels of proficiency and time allocations of a highly accomplished teacher. (The degree of shading in the planes represents the level of proficiency, and the arrows point to the percentage of time devoted to each plane of activity.) Reprinted with permission from Schoenfeld (2010) 
As teachers become more proficient at engaging their students, they spend less time on classroom management, both because they are better at it and because students who are actively engaged in doing mathematics do not need to be "managed" as much as those who are not productively engaged. Figure 2 provides the typical profile of an "accomplished" or "proficient" teacher.

Many teachers-perhaps the vast majority of experienced teachers in the US-have profiles as represented in Fig. 2. A much smaller percentage of teachers engage, to any significant degree, in diagnostic teaching. When it is well done, diagnostic teaching is very responsive to student understandings, and it is likely to be engaging; as a result, classroom management does not require much time and attention, and the students are involved in productive mathematical activities a large percentage of class time. This kind of teaching, when well done, results in a profile such as the one given in Fig. 3 .

From my perspective, a major challenge for professional development is to help teachers develop the resources, goals, and orientations that enable them to function in the ways represented in Fig. 3. As indicated above, this is of necessity a slow process: even if a teacher has aspirations to teach in a particular manner, it takes some time to develop the resources (e.g., pedagogical content knowledge) that support teaching in that way. Some beginning attempts to provide teachers with that kind of support are described below in the next section.

\section{Theorizing and implementing change}

Teachers' beliefs and orientations, like students' beliefs and orientations, are built up slowly from experience and are often not consciously held. Thus, they are slow to change, especially if the individuals are unaware of having them.

One of the student beliefs I documented many years ago (see, e.g., Schoenfeld, 1983, 1985) was that, on the basis of their experience in high school geometry courses, many students in the US come to believe that formal proofs are technical exercises that confirm what is already known or is empirically obvious, and thus that proof-related knowledge is irrelevant in the context of performing straightedge and compass constructions. (To be more precise, they behaved as if that is the case. The students solved proof problems, and then made conjectures about simple constructions that not only ignored, but actually contradicted what they had just proven.) The way I decided to confront this belief in my problem solving classes was to make it explicit, and then provide my students with enough empirical experience for them to build a new orientation toward the mathematics. Thus, I began one class by asking my students if they could tell me how to use straightedge and compass to bisect an angle. They gave me directions on how to perform the construction in just a few seconds. I then asked, "Why does the construction work?" After a minute or two they showed that the sequence of arcs that one draws to perform the construction creates two congruent triangles, so that the two parts of the original angle that are created by the construction are corresponding parts of congruent triangles (and thus equal).

I then asked them how to perform another common but more complex construction. Once again they gave me the directions; once again I asked why the construction works; and once again they were mystified at first but then created a proof.

At that point a student raised his hand and asked, "Are you trying to tell us that proofs are actually good for something?" I said yes, that was the point of the examples - to indicate to the students that many of them held the (previously unarticulated) belief that proof was not useful. Then, I said, we were going to work on a number of problems for which they would find proof a valuable tool. The problems (chosen from Chapter 1 of Pólya, 1981) were sufficiently complex that the students were not able to guess the solutions-but when they analyzed the properties of the objects they needed they were be able to determine the solutions.

This empirical experience, of engaging in problem solving activities in which proof and proving became productive tools for them, was essential in order to change the students' orientations toward proofs. Recognizing that they had that particular belief (that proofs are not useful when engaging in "discovery" problems) made it easier to counter the belief. But, the belief had been built on the basis of empirical experience and fit into a constellation of behaviors. It was necessary to develop a set of new habits and behaviors that enabled alternative orientations toward proof and constructions to take root. The same is the case with regard to teachers' orientations toward their pedagogical practices.

The first step on the path to diagnostic teaching is the recognition that it is productive to listen to student thinking - that taking the time to understand what students think can lead to productive instructional practices. As simple as this may seem, it is not a commonly held belief among teachers in the US. That is, most teachers focus on what they present to students, on whether the students appear to be actively engaged in doing the mathematics, and whether the students "get it" or not; their teaching is not aimed at being responsive to student (mis)understandings. Thus, in our recent professional development work, as part of the US National Research Council's National Research Council's Strategic Educational Research Partnership's (SERP's) collaboration with the San Francisco Unified 
School District (see http://www.serpinstitute.org/about/ field-sites/san-francisco.php), we began by exploring the space of student thinking with our collaborating teachers. Each teacher was given a tape recorder and asked to interview some of his or her students working a typical problem from the curriculum.

One seventh grade teacher chose to interview a particular student because she felt that the student should not be enrolled in her class. ${ }^{3}$ The school district had recently decided to place all seventh graders in "pre-algebra," regardless of the students' backgrounds. Their district's goal was to prepare all seventh grade students for a statemandated eighth grade algebra course. As a result, however, some students with very weak backgrounds were enrolled in seventh grade mathematics classes. According to the teacher, this particular student's homework had never revealed more than "chicken scratches on the page," providing no evidence that the student was following the material. The teacher decided to interview the student in order to get a better sense of what she knew and did not know. For the interview she chose a problem from the curriculum:

A five-pound box of sugar costs $\$ 1.80$ and contains

12 cups of sugar. Marella and Mark are making a

batch of cookies. The recipe calls for 2 cups of sugar.

Determine how much the sugar for the cookies costs.

Although the problem may appear simple, it offers many challenges to students who are not fluent in English. Students must understand what a batch of cookies is and that one recipe produces one batch; they must then sort through the wording in the problem to identify the underlying mathematical relationships involved. Many students had had difficulty with this problem, and the teacher expected this particular student to struggle. She asked the student to read through the problem and then to think out loud as she worked on its solution.

I begin by reproducing the student's written work, in Fig. 4. This is the kind of evidence this teacher typically had available, to judge what students understand. Note that many teachers in the US teach five or six classes of mathematics each day, with 30 or so students in each class. If they collect the students' work to grade, they have 150-180 papers to examine. This means that the amount of time they can devote to each paper is minimal.

The reader might try to analyze the student's written work. It offers a significant challenge! Why is $18-12=4$ ? Just what is the number .13 .3 ? Why is $13.3+13.3=.26 .6$ ?

Here is what happened in the interview.

\footnotetext{
3 This discussion is adapted from Schoenfeld (2011).
}

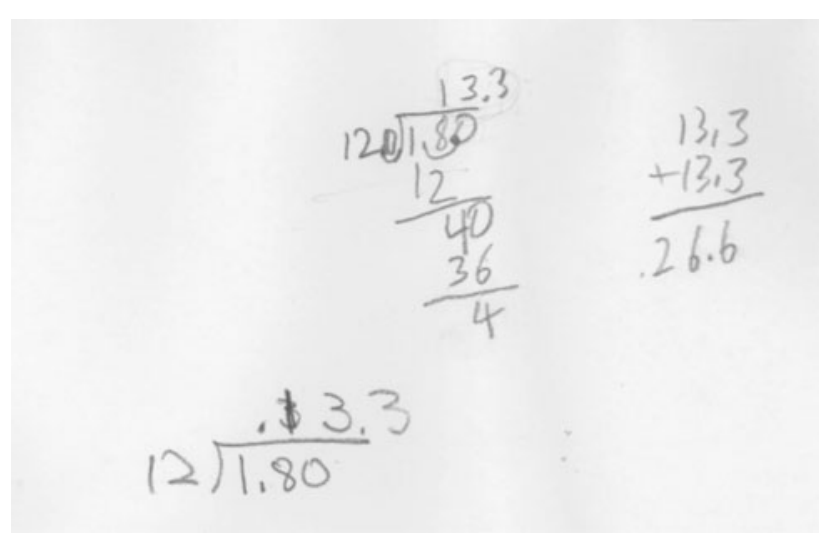

Fig. 4 The student's work

The student read the problem and immediately said "So it'll be one dollar and eighty cents divided by twelve." Having said that, she produced the computations in Fig. 4, and then stopped to look over what she had done. The teacher asked the student if she thought the answer was right, and the student said no. As the student began to re-do the computation ("so twelve into one eighty is...") the following dialogue took place:

T: So you like a dollar eighty divided by 12 . Do you think that's right?

S: Yeah

T: So how did you know to do that?

$\mathrm{S}$ : Because 12 is, the 12 cups of sugar is one dollar and eighty cents, it will cost one dollar eighty cents... so I got how much it will cost for one cup of sugar, so then add one cup to another cup to get this (pointing to the .26.6)

T: OK, good, I get that. So now what are you trying to figure out?

S: What I did wrong ... the cup. (Points to the 13.3.)

$\mathrm{T}$ : And how do you know you did something wrong?

S: Because the answer's too much, it's like over the one eighty

T: Oh I see, so 2 cups of sugar couldn't cost more than 12 cups of sugar/

S: Yeah

T: /so that's how you know it's wrong. So what are you going to do to figure out what you did wrong?

S: Go back and check it

The dialogue makes it clear that the student understood what she needed to do in order to get the correct answer: she had to divide $\$ 1.80$ by 12 to get the cost of one cup of sugar, and then double it to get the cost of the sugar needed for the recipe. Moreover-and unlike many students-the student checked the reasonableness of her answer. She knew she had done something wrong because the 
numerical value she had obtained was not consistent with the information in the problem statement.

When the teacher played the tape of the interview to the SERP meeting, she was excited about what she had learned. "I thought the student didn't belong in the class," she said. "All I'd seen were chicken scratches on the page. But now I see she totally gets it conceptually; she just has problems with the algorithms. She definitely belongs in the class, I can do remediation on the algorithms."

At that point the teacher paused, shook her head, and said: "I had a completely wrong impression of her... Oh my god, I'm going to have to interview all my students!"

This kind of experience, shared with other teachers, helped to bring the utility of looking at student thinking out into the open. But, as in the case of the student discussion of proofs, awareness is only a first step. The issue, once the teachers' orientations have been made an object of discussion, is to provide a set of experiences that will serve as the anchor for a set of alternative orientations toward teaching. As discussed above, the kind of change discussed here takes time to occur: habits of mind will evolve with habits of pedagogy, and those in turn will evolve slowly as the teachers build new sets of resources with which to implement them. (Recall Cohen's (1990) description of Mrs. Oublier: Mrs. Oublier had adopted the language of mathematics reform, but she still depended on her pedagogical repertoire, which in many ways undercut the new goals she espoused.) Thus, in our professional development work, we looked for ways to capitalize on the teachers' awareness of the value of examining student thinking. Some of what we tried was productive, some less so; we are now embarking on a next phase of work, grounded in what has been done thus far. What follows is a brief description of some of those efforts.

One productive step arose from a teacher's interview with a student about the following proportionality problem:

A dragonfly, the fastest insect in the world, can fly 50

feet in 2 seconds. How long does it take the dragonfly to fly 375 feet?

Immediately after reading the problem out loud, the student said,

"So, first I'll divide 375 with 50, and then - wait ... (5 second pause) ... Or, I will multiply... like 50 ... no wait, now what? This is dividing ... 5 times what can get 8 ?"

It was clear to the teacher conducting the interview that the student had not developed a mathematical understanding of the situation. Rather, because rates were involved, the student had decided that either multiplication or division would be used; he guessed at which numbers and which operation to try, without thinking through why. The teacher tried to get the student to slow down, but it was very hard to focus the student on the substance of the problem, rather than the mathematical operations. After more than $6 \mathrm{~min}$ of questioning-the teacher asked numerous times, "what information do you have and what are you trying to find?" - the student finally came to grips with what the problem asked. At that point his approach changed from something the SERP teachers have called "number mashing" (taking the numbers in the problem statement, selecting an operation and applying it) to something sensible. If the dragonfly can fly 50 feet in $2 \mathrm{~s}$, he reasoned, then it can fly 100 feet in $4 \mathrm{~s}$, and so on.

Our discussions of this student's work were productive in a number of ways. One is that all of the teachers in our group, when they listened to the tape of the interview, recognized the student's behavior. Number mashing was a very familiar phenomenon. Given that, what might we do in order to prevent it? One of the teachers suggested that we might address the problem by depriving students of the opportunity to mash numbers. Rather than giving a question and expecting them to find an answer, we would give them a situation and ask them to create and discuss a meaningful mathematics question that could be answered with the given information. Thus, the dragonfly problem given above was transformed into the following:

"A dragonfly, the fastest insect in the world, can fly

50 feet in $2 \mathrm{~s}$. Make up a meaningful mathematics problem that uses this information. Explain why your problem makes sense and how you would think about solving it."

Not only does this technique, which we call "using problem stems," slow the students down, it provides teachers with opportunities to see what the students consider to be important in the situation and how they put the mathematics together.

A second productive outcome of the dragonfly problem was that the tape of the student interview gave us an opportunity to discuss the mathematical approach the student did use when he finally slowed down enough to understand the problem. The approach the student took"if the dragonfly can fly 50 feet in 2 seconds, then it can fly 100 feet in 4 seconds," and so on-is additive rather than multiplicative. This approach certainly can be used to arrive at an answer, but the process is cumbersome and inefficient. What the problem was intended to reinforce, we assumed, was the idea of proportional reasoning and/or the idea of rates. If one understands proportionality and assumes that the dragonfly continues to move at a constant speed, then one can set up the simple ratio 


\section{$5 \underline{0 \text { feet }}=\underline{375 \text { feet }}$}

2 seconds $\mathrm{x}$ seconds,

which can be solved without difficulty. Or, and perhaps better, one might look for a convenient unit. Once one realizes that the dragonfly's speed is 25 feet per second, it is easy to see that it travels $25 t$ feet in $t$ seconds, or that it travels $d$ feet in $d / 25 \mathrm{~s}$. This, presumably, is the mathematics that the students were expected to work with on the problem. Recognizing that the additive approach bypasses this mathematics enabled the teachers to re-think their approaches to the content, and to help the students make the transition from the additive approach to the more sophisticated (and grade-appropriate) perspectives.

Problem stems thus serve two purposes. First, they slow students down, helping the students focus more on sense making than on getting answers. Second, they provide opportunities for students to reveal their current understandings, and thus help the teachers build on their actual understandings. The dragonfly problem deals with very simple mathematics, but the approach is generic: the information in very complex problems can be revealed one piece at a time, and students can be asked, with each new piece of information, what sense they can make of the situation and what kinds of questions they can and cannot answer with the given information.

A less productive outcome came from our discussion of another problem, also taken from the curriculum. This is the problem:

A train left the station going $50 \mathrm{mph}$. Three hours later, another train left the station going $60 \mathrm{mph}$ in the same direction. How long will it take the second train to overtake the first train?

There are various ways to solve the problem. It can be done by:

- making a table showing where each train is each hour after the second train departs;

- making a graph showing the positions of both trains;

- setting up and solving a pair of simultaneous equations;

- noting that the second train, once it is in motion, "catches up" 10 miles each hour, and using that fact to determine how long it takes to compensate for the first train's lead.

Some minor issues must be attended to when one adopts each of these approaches, for example determining (and keeping track of) at what point one starts counting time-is it when the first train leaves, or the second? More interesting is noting the connections among the various approaches. Where do the expressions that one writes in the simultaneous equations appear in the graphs? Where does the difference of $10 \mathrm{mph}$ appear in the equations, and in the graphs?

In the SERP seminar, a very sophisticated facilitator led a discussion of this problem. He had the participants solve the problem in pairs, and write up their solutions on posters. When he discussed the solutions, he began with the least sophisticated solutions (using charts) and raised issues about the mathematics in their solutions-e.g., when the people who produced the posters had set $t=0$, what were their assumptions? When the group was confident that they understood those posters, he moved to the graphs. He worked through similar issues, and then asked the seminar what connections they could make between the tables and the graphs. This continued with a discussion of the equations, and of the "catching up" approach.

The discussion was a tour de force. As a participantobserver, I saw the way in which the facilitator used the posters as a means of getting participants to reveal their understandings, and how he got them to build on them and make connections. Those with the least sophisticated solutions saw how their ideas could grow to include the other approaches, and those with the most sophisticated solutions were pushed to see connections and develop understandings that made their grasp of the content more robust.

The facilitator had deliberately chosen a problem from the curriculum, so that the teachers could use it themselves. The idea was that his session modeled the processes we hoped the teachers would use. The teachers would (a) diagnose the strengths and weaknesses of the student work, (b) ask probing questions and make comments that reveal and address the students' misconceptions and build on the understandings they have, (c) make as many connections as possible, so that the entire session served as an exercise in sense making. What happened, however, was that teachers (who were still early in the process; this was still early in the seminar) took the facilitator's actions as a script - a sequence of activities to be replicated-rather than as a guide to interacting with what their students produced in the moment. Implemented in this way, the lesson lacks power, because it does not build effectively on student knowledge.

In hindsight, that the teachers did this should not be surprising. Acting in a way consistent with the facilitator's actions and intentions demands a set of knowledge and skills that the participants in the seminar had not yet developed. Moreover, the rationale for much of what he did was tacit rather than explicit. To expect the participants to act on the principles he acted on was to expect far too much, both because the shift in orientation was significant and because implementing the lesson in the way he did depended on a body of resources not readily available to 
the teachers. As noted above, resources, goals, and orientations all co-evolve slowly. This fact imposes serious constraints on any proposed set of professional development activities.

We are currently planning a set of activities that we hope is more consistent with the ideas about orientations and the nature of change discussed above. The idea is for the seminar participants to create and reflect on a set of materials intended to facilitate the process of diagnostic teaching. Specifically,

(i) orientations goals, and resources exist in (positive or negative) synergy, so they must all be addressed at the same time;

(ii) changes in orientations are more likely to take place, and more likely to last, if they are discussed overtly and the support structures for them become part of regular teaching practice.

We have, thus, set for ourselves the following goals. Participants in the seminar (which includes researchers, professional developers, and teachers) plan to craft a set of support materials for six diagnostic lessons at each grade level that focus on the "big ideas" of the curriculum. The process of crafting those materials begins with the selection of the topics and research (by the researchers in the team) on typical student difficulties and how to identify and approach them.

We will then construct tasks that are likely to reveal student understandings and misunderstandings, and we will produce a package of materials that explains both the mathematical goals for the lessons and how the tasks can be used. Prior to teaching the lessons, teachers will be interviewed about why they are doing what they are doing, what they expect the tasks to reveal, and how they expect to address what they learn from the tasks. They will be taped as they teach each lesson, and "debriefed" on tape after the lesson. The materials, the interviews, the classroom tapes, the debriefing interviews, and revised materials based on the experience will all be made available to teachers throughout the district.

The general scheme to be followed here is analogous to the process I discussed at the beginning of this section with regard to helping students develop a deeper understanding of mathematical proof. The first step is to make the underlying assumptions explicit-in the case of proof, that proving is a productive way to think mathematically; in the case of teaching, that diagnostic teaching is a powerful way to engage students and help them learn. But the second, much more critical step is to provide an experiential base that supports the desired orientations and helps the participants to develop the habits and habits of mind consistent with them. In the case of geometry, the experience was to work a series of problems in which proof became a helpful tool in problem solving. In the case of teaching, the experience will be to teach a series of well scaffolded lessons in which student thinking is the focus and the teachers can build on it productively. The third step is conscious reflection on the process. The students' orientation toward geometry and problem solving was an ongoing topic in my problem solving courses. In the current effort, the pre-instruction interviews, the debriefings, and the collective efforts to revise the materials will provide grist for reflection on our collective efforts and the rationale for them.

This will be an experiment at two levels. For the teachers participating in the SERP seminar it will be an intensive experience, which we can look at "under the microscope." One hopes that there will be changes in their orientations, goals, and resources, documenting what happens will be an interesting challenge. (Consistent with my theoretical orientations as explained in Sect. 2, the real question is whether there are ongoing changes in the teachers' practices, not merely professions of changed orientations.) Much more of a challenge is to see whether the materials developed by SERP participants will have any impact on teachers who have not participated in the seminar. The materials will become part of the district's curriculum, so teachers will be induced to use them. Use is not enough, however; as the case of Mrs. Oublier indicates, it is almost inevitable for such materials, without additional support, to be assimilated into teachers' regular practices.

That is the reason for the varied support materialsinterviews, classroom tapes, debriefings, etc. The kind of intensive seminar we have conducted with the teacherdevelopers is far too expensive to conduct on a districtwide scale. Whether the materials and videotapes we produce can provide enough of a vicarious experience to have an impact on teachers across the district is very much an open question. The attempt will, at least, provide us with the opportunity to delve more deeply into the complexities of teachers' resources, goals, and orientations, and how they might be shaped by the teachers' experiences.

Open Access This article is distributed under the terms of the Creative Commons Attribution Noncommercial License which permits any noncommercial use, distribution, and reproduction in any medium, provided the original author(s) and source are credited.

\section{References}

Aguirre, J., \& Speer, N. M. (2000). Examining the relationship between beliefs and goals in teacher practice. Journal of Mathematical Behavior, 18(3), 327-356.

Berliner, D. C., \& Calfee, R. C. (Eds.). (1996). Handbook of educational psychology. New York: Macmillan.

Borko, H., Eisenhart, M., Brown, C., Underhill, R., Jones, D., \& Agard, P. (1992). Learning to teach hard mathematics: Do 
novice teachers and their instructors give up too easily? Journal for Research in Mathematics Education, 23(3), 194-222.

Borko, H., \& Putnam, R. (1996). Learning to teach. In D. C. Berliner \& R. C. Calfee (Eds.), Handbook of educational psychology (pp. 673-708). New York: Macmillan.

Calderhead, J. (1996). Teachers: Beliefs and knowledge. In D. C. Berliner \& R. C. Calfee (Eds.), Handbook of educational psychology (pp. 709-725). New York: Macmillan.

Clark, C., \& Peterson, P. (1986). Teachers' thought processes. In M. C. Wittrock (Ed.), Handbook of research on teaching (3rd ed., pp. 255-314). New York: Macmillan.

Cohen, D. (1990). A revolution in one classroom: The case of Mrs Oublier. Education Evaluation and Policy Analysis, 12(3), 311-329.

Darling-Hammond, L. (Ed.) (1994). Review of Research in Education (Vol. 20). Washington, DC: American Educational Research Association.

Fennema, E., \& Franke, M. (1992). Teachers' knowledge and its impact. In D. Grouws (Ed.), Handbook of research on mathematics teaching and learning (pp. 147-164). New York: Macmillan.

Fernandez, C., \& Yoshida, M. (2004). Lesson study: A Japanese approach to improving mathematics teaching and learning. Mahwah, NJ: Erlbaum.

Fuller, F. (1969). Concerns of teachers: A developmental conceptualization. American Educational Research Journal, 6, 207-226.

Grouws, D. A. (Ed.). (1992). The handbook of research on mathematics teaching and learning. New York: MacMillan.

Hatano, G., \& Inagaki, K. (1986). Two courses of expertise. In H. Stevenson, J. Azuma, \& K. Hakuta (Eds.), Child development and education in Japan (pp. 262-272). New York, NY: W. H. Freeman \& Co.

Hord, S. M., Rutherford, W. L., Huling-Austin, L., \& Hall, G. E. (1987). Taking charge of change. Alexandria, VA: Association for Supervision and Curriculum Development.

Kahneman, D., Slovic, P., \& Tversky, A. (Eds.). (1982). Judgment under uncertainty: Heuristics and biases. Cambridge: Cambridge University Press.

Leder, G. C., Pehkonen, E., \& Torner, G. (Eds.). (2002). Beliefs: A hidden variable in mathematics education. The Netherlands: Kluwer Academic Publishers.

Lester, F. (Ed.). (2007). Second handbook of research on mathematics teaching and learning. Charlotte, NC: Information Age Publishing.

Munby, H., Russell, T., \& Martin, A. (2001). Teachers' knowledge and how it develops. In V. Richardson (Ed.), Handbook of research on teaching (4th ed., pp. 877-904). Washington, DC: American Educational Research Association.

National Council of Teachers of Mathematics. (1991). Professional standards for teaching mathematics. Reston, VA: NCTM.

Newell, A., \& Simon, H. (1972). Human problem solving. Englewood cliffs, NJ: Prentice-Hall.

Philipp, R. (2007). Mathematics teachers' beliefs and affect. In F. Lester (Ed.), Handbook of research on mathematics teaching and learning (2nd ed., pp. 257-315). Charlotte, NC: Information Age Publishing.
Pólya, G. (1981). Mathematical discovery (combined paperback edition). New York: Wiley.

Richardson, V. (2001). Handbook of research on teaching (4th ed.). Washington, DC: American Educational Research Association.

Ryan, K. (1986). The induction of new teachers. Fastback of Phi Delta Kappa Educational Foundation (No. 237).

Savage, L. J. (1954). The foundations of statistics. New York: Wiley.

Schoenfeld, A. H. (1983). Beyond the purely cognitive: Belief systems, social cognitions, and metacognitions as driving focuses in intellectual performance. Cognitive Science, 7 , 329-363.

Schoenfeld, A. H. (1985). Mathematical problem solving. Orlando, FL: Academic Press.

Schoenfeld, A. H. (1998). Toward a theory of teaching-in-context. Issues in Education, 4(1), 1-94.

Schoenfeld, A. H. (2002). How can we examine the connections between teachers' world views and their educational practices? Issues in Education, 8(2), 217-227.

Schoenfeld, A. H. (Ed.). (2008). A study of teaching: Multiple lenses, multiple views. (Journal for research in Mathematics Education monograph Number 14). Reston, VA: National Council of Teachers of Mathematics.

Schoenfeld, A. H. (2010). How we think. New York: Routledge.

Schoenfeld, A. H. (2011). Noticing matters. A lot. Now what? In M. G. Sherin, V. R. Jacobs, \& R. A. Philipp (Eds.), Mathematics teacher noticing: Seeing through teachers' eyes. New York: Routledge (in press).

Schoenfeld, A. H. (Special Issue Editor). (2000). Examining the complexity of teaching. Special issue of the Journal of Mathematical Behavior, 18(3).

Schraw, G., \& Olafson, L. (2002). Teachers' epistemological world views and educational practices. Issues in Education, 8(2), 99-148.

Shulman, L. S. (1986). Those who understand: Knowledge growth in teaching. Educational Researcher, 17(1), 4-14.

Shulman, L. S. (1987). Knowledge and teaching: Foundations of the new reform. Harvard Educational Review, 57, 1-22.

Smith, B. P. (2000). Emerging themes in problems experienced by student teachers: a framework for analysis. College Student Journal. Downloaded 20 Apr, 2009, from http://findarticles.com/ p/articles/mi_m0FCR/is_4_34/ai_69750211/.

Speer, N. M. (2005). Issues of methods and theory in the study of mathematics teachers' professed and attributed beliefs. Educational Studies in Mathematics, 58(3), 361-391.

Stigler, J., \& Hiebert, J. (1999). The teaching gap. New York: Free Press.

Swan, M. (2006). Collaborative learning in mathematics: A challenge to our beliefs and practices. London: National Research and Development Centre for Adult Literacy and Numeracy and National Institute of Adult Continuing Education.

Thompson, A. (1992). Teachers' beliefs and conceptions: A synthesis of the research. In D. Grouws (Ed.), Handbook of research on mathematics teaching and learning (pp. 127-146). New York: Macmillan.

Wittrock, M. C. (1986). Handbook of research on teaching (3rd ed.). New York: Macmillan. 